\title{
INTRODUCTION
}

\section{The Necessary and Dual Conversations in a Vibrant SoTL}

The first two issues of Teaching \& Learning Inquiry consisted of responses to specific questions about SoTL (1.1) and essays by the International Collaborative Writing Groups exploring specific facets of SoTL (1.2). We in the field devote much time, space, and copy to evaluating and theorizing SoTL (in addition to reporting on the work itself). We do this, not to belabor already exhausted topics or to suggest an immaturity of the field; instead, this meta-SoTL chronicles and even celebrates its ongoing sense of becoming and its confluence of diverse and serious inquiries from specific contexts. This vibrancy is both a source and consequence of what Phipps and Barnett (2007) call "academic hospitality," our "social bondedness" characterized by openness, responsibility, exploration, and neighborliness (p. 253). It's necessary in a field populated largely by scholars - "hosts," "guests," "guides," "tourists," and scouts—traveling outside of their home disciplines, nations, methodologies, communities, and even languages. These features require diligence to our borders, our mores, our identities. At the same time, we value getting out into the field, so we also seek out and celebrate the travelogues and field reports from our colleagues - or the SoTL work itself, the original research on teaching and learning.

The current issue (2.1) now takes us out into the field by featuring seven essays reporting on SoTL projects straight from the classroom. Each, in its own way, invites us to reflect on our roles as teachers and the learning partnerships we strike up with our students. First, Jeff Bernstein and Earle Abrahamson provide thoughtful reviews of a new book that helps readers hone their skills and knowledge related to teaching and to the ways students approach their learning. We are thus reminded of this shared responsibility of teacher and student, the synergy between teacher and learner, rather than just one or the other. Lane Glisson, Shane McConnell, Mahatapa Palit, Jason Schneiderman, Cynthia Wiseman, and Lyle Yorks started with a question about what they needed to get students to do in order to become better learners. They concluded that there were steps they themselves had to take first to help students get where they needed to go. Similarly, Daniel Bernstein and Andrea Follmer Greenhoot implemented an extensive project in which they created learning tasks so that students became better critical thinkers and analysts. Dana Lynn Driscoll documents a student attitude toward general education we've resisted and complained about, but rather than simply rehashing these typical conversations and blaming the students, she first shows us what it looks like in the students' own words: it's not as simple as we may assume. Then, as a result of listening directly to the students, she offers three specific "meta-education" strategies faculty and staff may take to help students 
shift away from these approaches, reminding us that we have both the duty and influence over students' beliefs about their learning. Lindsey N. Kingston, Danielle MacCartney, and Andrea Miller established communities of practice among students to help them explore human rights issues in much greater depth than would have been the case outside of these communities. Ultimately, these structures-designed by the faculty-created the most effective space and time for students' exploration of human rights education. Amanda Sturgill and Phillip Motley's article on service learning is about the role of reflective writing as an essential component, and they study the involvement of faculty in those reflections (guided, dialogic), concluding that faculty involvement at the front end (guiding the reflections) or during the process (dialogic process of responding to reflections) is more effective.

The previous essays emphasize the teacher's role in constructing effective learning environments and strategies for students. Linda Allin strives for a working relationship that is less about a sense of authority and more about co-discovery with students. Compellingly, she goes further to explore the limits and possibilities of partnering with students in pedagogy and SoTL research, given the hierarchies and power imbalances inherent in higher education. Finally, Rachel Foot, Alicia R. Crowe, Karen Andrus Tollafield, and Chad Everett Allan address and embody the ultimate in the notion of shared authority: they are graduate students studying their own development, serving as both researchers and subjects. Their essay thus fulfills the promise in TLI's mission to "showcase the breadth of the interdisciplinary field of SoTL in its explicit methodological pluralism, its call for traditional and new genres, and its international authorship from across career stages."

Nancy Chick is Assistant Director of the Center for Teaching and an affiliated faculty member in the English Department at Vanderbilt University.

Gary Poole is the Associate Director of the School of Population and Public Health and a Senior Scholar in the Centre for Health Education Scholarship at the University of British Columbia.

\section{REFERENCES}

Phipps, A., \& Barnett, R. (2007). Academic hospitality. Arts \& Humanities in Higher Education, 6(3). 237-254. 